\title{
Rational reduction of work in progress when assembling parts of a product using the group interchangeability method
}

\author{
Sergey Shilyaev ${ }^{*}$, Evgeniy Slashchev ${ }^{1}$, Igor Voyachek ${ }^{2}$ and Rinat Shaikhov ${ }^{3}$ \\ ${ }^{1}$ Izhevsk State Technical University, 7, Studencheskaya street, Izhevsk, 426069, Russia \\ ${ }^{2}$ Penza State University, 40, Krasnaya street, Penza, 440026, Russia \\ ${ }^{3}$ Perm State Agro-Technological University, 23, Petropavlovskaia street, Perm, 614990, Russia
}

\begin{abstract}
The article discusses the method for interchangeability method. To reduce the volume of work in progress, the design of a fixed combined compensator is developed, which provides stepwise regulation. The article reducing the work in progress by stepwise regulation in multilink dimension chains when assembled using the group proposes a rational technology for the use of combined compensator, taking into account the peculiarities of the group interchangeability method. In order to reduce the work in progress during assembly using the group interchangeability method, two ways of using the combined compensator have been developed: 1 - the inclusion of a compensator in each dimensional chain collected by the group interchangeability method; 2-application of the compensator only at the stage of formation of work in progress during group assembly by replacing one of the parts with it. The peculiarity of the methods is the use of the informational advantage of group assembly information about the actual dimensions necessary for sorting parts into groups. This eliminates the step of measuring the closing link during assembly and simplifies the design of the compensator, reducing the number of control steps.
\end{abstract}

\section{Introduction}

One of the most important tasks of improving the method of group interchangeability when assembling machine components is to reduce the volume of work in progress $[1-10,15]$. The main methods of reducing the volume of work in progress when using the method of group interchangeability include the method of intergroup interchangeability, the method of individual selection of parts and the method of stepwise regulation using compensators.

The intergroup interchangeability method developed in the $70 \mathrm{~s}$ of the last century provides dividing the tolerance range of coupling sizes into smaller selective intervals. In this connection, additional sorting kits are formed, passing through one selection group $[16,17]$. Significant disadvantages of this method include:

\footnotetext{
* Corresponding author: shiljaev@mail.ru
} 
1) with the method of tolerances of the same quality, picking is possible only with partial compensation for work in progress, as there are different acquisition intervals for parts of the increasing and decreasing links;

2) compared with the group interchangeability method, the number of sorting operations increases significantly; This method is rational to use only in dimensional chains with two component links;

3) the use of the intergroup interchangeability method is rational with the possibility of breaking down the smallest group tolerances taking into account the measurement error;

4) the high complexity of parts sets control and the complexity of the automatic in-line assembly organization due to the additional acquisition of adjacent groups.

The method of individual selection of parts takes into account various errors and parameters of the mating parts when acquisition of assembly units [11-14]. Acquisition takes place with the help of automated control devices taking into account the selection of the best sorting option. The criteria for the effective application of this method can act as a decrease in the volume of work in progress, and the achievement of other specified characteristics of the assembly. The disadvantages of this method are high complexity of acquisition, the inability to use when a big number of links in the dimensional chain, and the need for specialized tools to determine the parameters of the mating parts. In order to reduce the disadvantages of these methods, stepwise regulation is used for multilink dimension chains [18-24].

\section{Ways to reduce the volume of work in progress by stepwise regulation during assembly using the method of group interchangeability.}

Figure 1 shows a general view of the developed precast compensator, which provides stepby-step adjustment of the size of the closing link.

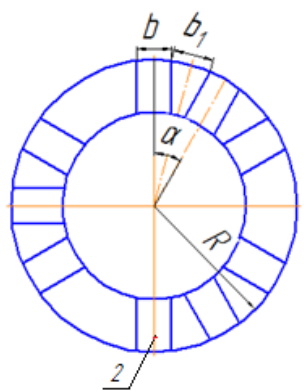

a)

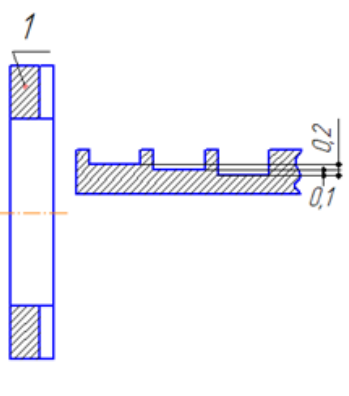

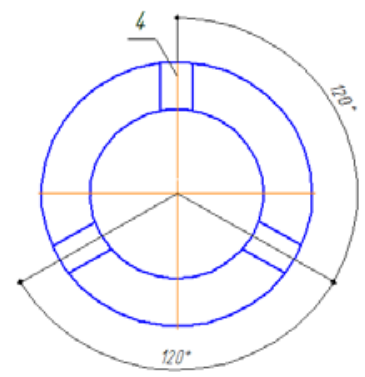

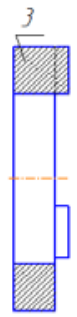

b)

Fig. 1. Compensator: a) ring (1) with measuring groove (2); b) ring (1) with identical protrusions (2)

If the number of parts in the respective groups is the same when assembling dimension chains using the group interchangeability method, no compensation is needed. Work in progress is absent. In the case where the number of parts in the respective groups is different when dividing into groups, work-in-progress occurs and compensation is necessary to reduce or eliminate it. At the same time, there are two ways to apply stepwise regulation using fixed compensators:

1) the inclusion of a compensator in each dimensional chain, built by the method of group interchangeability; 
2) the use of a compensator only at the stage of formation of work in progress during group assembly by replacing one of the parts with it. The first method involves the initial replacement of one of the parts on the combined compensator, which is also divided into groups by the size between the outer end surfaces. In this case, the design becomes merely complicated, but the production in progress is completely absent. It is useful to apply the method in small-scale production or when a single batch is made.

The second method involves the use of a compensator only at the stage of production in progress. In this case, the compensator replaces one of the parts, the most suitable in form. Work in progress takes place in the form of the remaining parts replaced by the compensator. But in the manufacture of the following batches of parts, this can be taken into account. The right amount of compensators is also known. It corresponds to the number of products that remain unassembled by the classical method of group interchangeability. It should be noted that stepwise regulation in the implementation of these methods is used in combination with the group interchangeability method. As a result there is a significant informational advantage - the actual dimensions of the parts are known, according to which they were divided into groups. A combination of actual dimensions in a particular dimensional chain or the worst and best combination of the actual dimensions of parts at the stage of work in progress is known. It is the information that should be used to select the appropriate compensation stage when implementing the first method and to determine the compensation stages when implementing the second one. Since the actual dimensions of the parts in a particular chain are known, then the calculation (and not measurement) determines the desired level (slot size) when assembling the compensator.

\section{An example of reducing the volume of work in progress by stepwise regulation during assembly method of group interchangeability}

The combination of the method of group interchangeability and regulation will be considered with a definite example.

\section{The first way:}

A sketch of the assembled structure is shown in Figure 2. Maximum and minimum and clearance (closing link) $\mathrm{A}_{\Delta \max }=\mathrm{S}_{\max }=0.24 \mathrm{~mm}, \mathrm{~A}_{\Delta \min }=\mathrm{S}_{\min }=0.12 \mathrm{~mm}$. The clearance tolerance TS $=0.12 \mathrm{~mm}$.

The nominal dimensions of the links of the dimensional chain: $A_{1}=22 \mathrm{~mm}, \mathrm{~A}_{2}=16$ $\mathrm{mm}, \mathrm{A}_{3}=22 \mathrm{~mm}, \mathrm{~A}_{4}=60 \mathrm{~mm}$.

If we use the method of complete interchangeability during assembly, then the average tolerance for the manufacture of links $T A i=0.025 \mathrm{~mm}$, which is economically inefficient, in this regard, extended tolerances are assigned: $T A_{4}=0.24 \mathrm{~mm} ; T A_{3}=0.08 \mathrm{~mm} ; T A_{2}=$ $0.08 \mathrm{~mm} ; T A_{1}=0.08 \mathrm{~mm}$. When assembling it is rationally to apply the method of group interchangeability. Ensuring the accuracy of the assembly method of group interchangeability $T D=T d=0.24 \mathrm{~mm}$. 


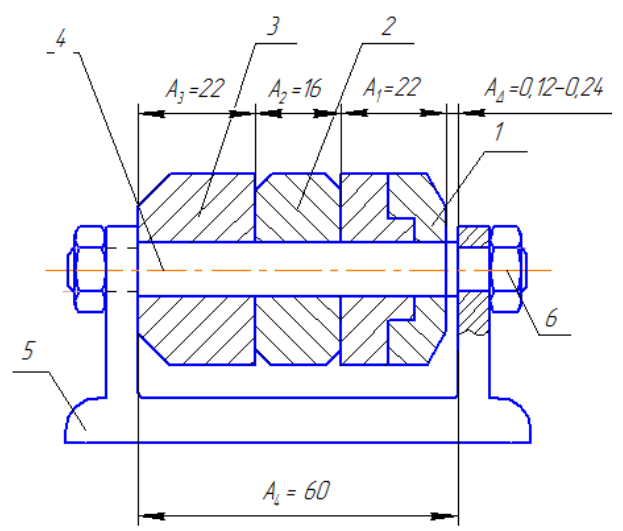

Fig. 2. Sketch of the design of the sharpening mechanism: 1 - assembly unit - compensator; 2 - guide ring; 3 - grinder; 4 - axis; 5 - body; 6 nut.

Find a group admission $T_{g r}(1)$ :

$$
\mathrm{T}_{\mathrm{gr}}=T S / 2=\frac{S_{\max }-S_{\min }}{2}=\frac{0.12}{2}=0.06 \mathrm{~mm},
$$

the number of groups $n=T D / T_{g r}=0.24 / 0.06=4$, the equality of the sums of the tolerances of the increasing and decreasing links is checked: $T D=T d=0.24 \mathrm{~mm}$, the upper and lower deviations are calculated according to the recurrent formulas 2.3 for increasing and 4.5 for reducing links.

for increasing link (Eq.2,3):

$$
\begin{aligned}
E S \overrightarrow{A_{4}(i)} & =T D\left(1-\frac{i-1}{n}\right), \\
E S \overrightarrow{A_{4}(i)} & =T D\left(1-\frac{i}{n}\right),
\end{aligned}
$$

where $i=1,2 \ldots \mathrm{n}$ is the current variable characterizing the groups number.

$\operatorname{ES} \overrightarrow{A_{4}(1)}=0.24\left(1-\frac{1-1}{4}\right)=0.24 \mathrm{~mm}, \operatorname{ES} \overrightarrow{A_{4}(2)}=0,24\left(1-\frac{2-1}{4}\right)=0,18 \mathrm{~mm}$,

$E S \overrightarrow{A_{4}(3)}=0,12 ; E S \overrightarrow{A_{4}(4)}=0,06 \mathrm{~mm}, \operatorname{EI} \overrightarrow{A_{4}(1)}=0.24\left(1-\frac{1}{4}\right)=0.18 \mathrm{~mm}$,

$E I \overrightarrow{A_{4}(2)}=0.24\left(1-\frac{2}{4}\right)=0.12 \mathrm{~mm}, \quad E I \overrightarrow{A_{4}(2)}=0.06 \mathrm{~mm}, \quad$ EI $\overrightarrow{A_{4}(2)}=0 \mathrm{~mm}$.

for reducing links (Eq.4,5):

$$
\begin{gathered}
e s \overleftarrow{A(i, j)}=\left(T d-T d / n-S_{\min }\right) \frac{\Pi_{k=2}^{m_{\text {red }}}(k-j)}{m_{\text {red }} !}-\frac{T d \cdot(i-1)}{m_{\text {red }} \cdot n}, \\
e i \overline{A(i, j)}=\left(T d-T d / n-S_{\min }\right) \frac{\prod_{k=2}^{m_{\text {red }}}(k-j)}{m_{\text {red }} !}-\frac{T d \cdot(i)}{m_{\text {red }} \cdot n},
\end{gathered}
$$

where $\mathrm{j}=1.2 \ldots \mathrm{m} ; \mathrm{k}=2.3 \ldots m_{\text {red }}$ - the current variables corresponding to the component links number $(\mathrm{m} \geq 2)$.

$$
\begin{aligned}
& \text { es } \overleftarrow{A(1.1)}=(0.24-0,24 / 4-0.12) \frac{(2-1)(3-1)(4-1)}{3 \cdot 2 \cdot 1}-\frac{0.24 \cdot(1-1)}{3 \cdot 4}=0.06 \mathrm{~mm}, \\
& \text { es } \overleftarrow{A(2,1)}=0,04 \mathrm{~mm}, \text { es } \overleftarrow{A(3.1)}=0.02 \mathrm{~mm} \text {, es } \overleftarrow{A(4,1)}=0 \text { etc. }
\end{aligned}
$$

The remaining data are summarized in table 1. 
Table 1. Results of solving the dimensional chain ( $\mathrm{mm})$

\begin{tabular}{|c|c|c|c|c|c|c|c|c|c|c|c|}
\hline \multirow{2}{*}{ Group } & \multicolumn{2}{|c|}{$\mathrm{A}_{3}=22$} & \multicolumn{2}{c|}{$\mathrm{A}_{2}=16$} & \multicolumn{2}{c|}{$\mathrm{A}_{1}=22$} & \multicolumn{2}{c|}{$\mathrm{A}_{4}=60$} & \multicolumn{2}{c|}{ Clearance } & \multirow{2}{*}{$T S$} \\
\cline { 2 - 13 } & $e s$ & $e i$ & $e s$ & $e i$ & $e s$ & $e i$ & $E S$ & $E I$ & $S_{\min }$ & $S_{\max }$ & \\
\hline 1 & 0 & -0.02 & 0 & -0.02 & 0.06 & 0.04 & 0.24 & 0.18 & 0.24 & 0.12 & 0.12 \\
\hline 2 & -0.02 & -0.04 & -0.02 & -0.04 & 0.04 & 0.02 & 0.18 & 0.12 & 0.24 & 0.12 & 0.12 \\
\hline 3 & -0.04 & -0.06 & -0.04 & -0.06 & 0.02 & 0 & 0.12 & 0.06 & 0.24 & 0.12 & 0.12 \\
\hline 4 & -0.06 & -0.08 & -0.06 & -0.08 & 0 & -0.02 & 0.06 & 0 & 0.24 & 0.12 & 0.12 \\
\hline
\end{tabular}

The layout of tolerances is shown in Figure 3.

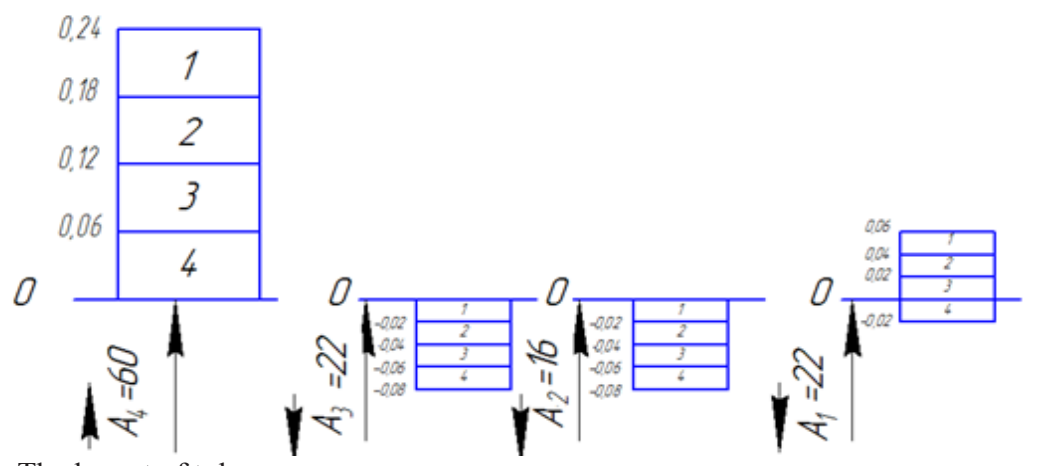

Fig. 3. The layout of tolerances

\section{Projecting the compensator design}

a) the compensation value is determined using the regulation method and formulas 6 and 7 , derived depending on the size of the upper and lower deviations of the dimension chain links (Eq. 6,7):

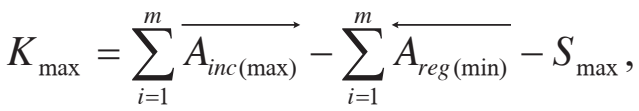

$$
\begin{aligned}
& K_{\text {min }}=\sum_{i=1}^{m} \overline{A_{i n c(\min )}}-\sum_{i=1}^{m} \overleftarrow{A_{\text {reg (max })}}-S_{\max },
\end{aligned}
$$

where $A_{\text {inc }}$ - increasing link, $A_{\text {reg }}$ - reducing link.

$K_{\max }=60.24-(21.98+15.92+21.92)-0.24=0.18 \mathrm{~mm} ; K_{\min }=60-(22.06+16+22)-0.12=0.18 \mathrm{~mm}$;

b) the number of compensation steps (slots) is determined (Eq.8):

$$
n_{1}=\left(K_{\max }-K_{\min }\right) / S_{\min }+1, n
$$

$n_{l}=(0.18+0.18) / 0.12+1=4$

c) the compensation change (from the zero initial position) of the dimensions of the stages and the dimensions of the li jumpers of the compensator are calculated (Figure 3): 0 stage: $\Delta_{\mathrm{k} 0}=0 ; l 0=5_{-0.02}^{0.02} \mathrm{~mm} ; 1$ stage: $\Delta_{\mathrm{k} 1}=+0.18 \mathrm{~mm} ; l 1=5.18_{-0.02}^{0.02} \mathrm{~mm} ; 2$ stage: $\Delta_{\mathrm{k} 2}=+0.06 \mathrm{~mm} ; l 2=5.06_{-0.02}^{0.02} \mathrm{~mm} ; 3$ stage: $\Delta_{\mathrm{k} 3}=-0.06 \mathrm{~mm} ; l 3=4.94_{-0.02}^{0.02} \mathrm{~mm} ; 4$ stage: $\Delta_{\mathrm{k} 4}=-0.18 \mathrm{~mm} ; l 4=4.82_{-0.02}^{0.02} \mathrm{~mm}$.

The size from the end of the compensator ring to the protrusion is equal to $l_{6}=17+$ $0.04 \mathrm{~mm}$

d) develop the design of the compensator (Figure 4). 


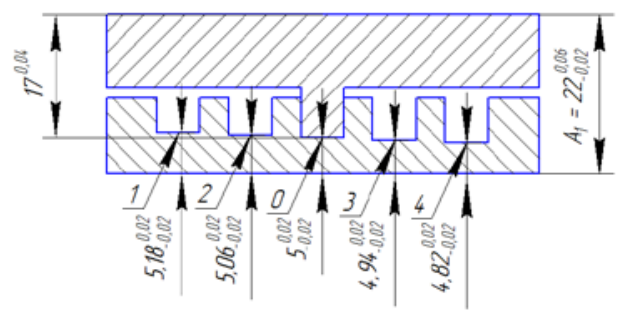

Fig. 4. Flat pattern of a compensator design with compensation steps

Sorting parts. The parts are sorted into containers for clarity and validation of the compensator design. 13 parts for each link are taken, sorted into 4 groups, indicated by dots (Figure $5 \mathrm{a}, \mathrm{b}$ ).

The ideal case

The real case

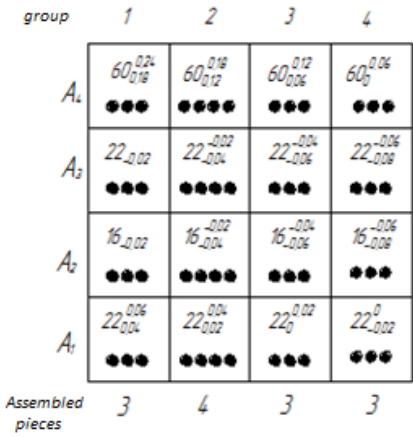

a)

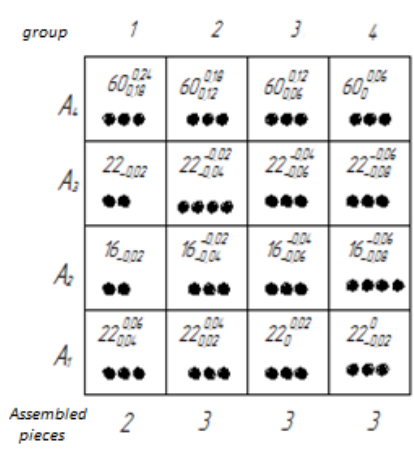

b)

Fig. 5. Model of the location of parts in the sorting container: a - the ideal case (the number of parts in the respective groups is the same, $100 \%$ assemblability, work in progress is absent), $\mathrm{b}$ - the real case (with work in progress).

It should be noted that in each dimensional chain there is an assembly unit as a link - a compensator, which is between the end surfaces of the rings $\mathrm{A}_{1}=22_{-0.02}^{0.06}$, is also sorted into groups. In this case, the zero position of the rings is realized (see Figure 4).

\section{Assemblability check is performed for the ideal and real case of sorting}

a) the assemblability of the ideal case is considered on the example of the group I: assemblability condition (Eq.9):

$$
S_{\min } \leq A_{\Delta i} \leq S_{\max }
$$

where $A_{\Delta i}$ - clearance after assembly (Eq.10,11):

$$
\begin{aligned}
\mathrm{A}_{\Delta \max } & =\sum_{i=1}^{m} \overrightarrow{A_{y s(\max )}}-\sum_{j=1}^{n} \overleftarrow{A_{y M(\min )}} \\
\mathrm{A}_{\Delta \min } & =\sum_{i=1}^{m} \stackrel{A_{y s(\min )}}{\longrightarrow}-\sum_{j=1}^{n} \overleftarrow{A_{y M(\max )}}
\end{aligned}
$$

where: $m$ is the number of increasing links in the dimensional chain (counter $i) ; n$ is the number of reducing links in the dimensional chain (counter $\mathrm{j}$ ),

$A_{\Delta \max }=60.24-21.98-15.98-22.04=0.24 \mathrm{~mm}$; 
$A_{\Delta \min }=60.18-22-16-22.06=0.12 \mathrm{~mm}$;

The condition $A_{\Delta \max }$ and $A_{\Delta \min }$ is satisfied, after the assembly of the product no sets remain in the container In the container sets does not remain.

b) assemblability for an arbitrary real case is considered (Figure 6).

$A_{\Delta \max }$ and $A_{\Delta \min }$ are calculated according to formula 10, 11:

$A_{\Delta \max }=60.24-21,96-15,92-22,04=0.32 \mathrm{~mm}$;

$A_{\Delta \min }=60.18-21.98-15.94-22.06=0.2 \mathrm{~mm}$;

Thus, there is a probability of non-compliance with the condition of assembly (9) in the case when the actual size of the closing link is in the range of $0.24 \mathrm{~mm}<A_{\Delta \partial} \leq 0.32 \mathrm{~mm}$

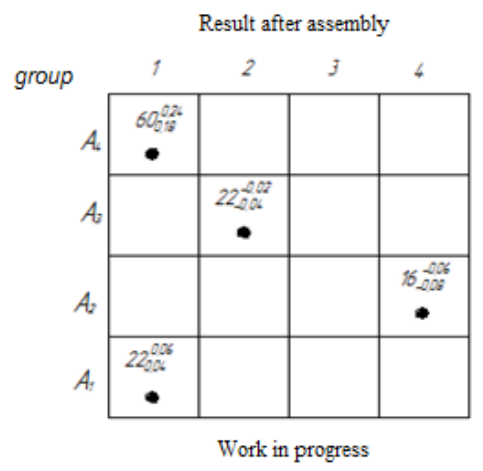

Fig. 6. Combination of groups of parts remaining after the group assembly

If, in order to eliminate work in progress and ensure the tolerance of the closing link, the size of the compensator is set on the first compensation stage, the link A1 will increase by $0.18 \mathrm{~mm}$. If the actual size of the closing link is in the range of $0.30 \mathrm{~mm} \leq \mathrm{A} \Delta д \leq 0.32 \mathrm{~mm}$, then the condition of assembly is fulfilled. If the actual size of the closing link is in the range of $0.2 \mathrm{~mm} \leq \mathrm{А} \Delta д<0.30 \mathrm{~mm}$, then the condition of assembly is not fulfilled. In this case, it is necessary to use information about the known actual sizes of the links, which is obtained by dividing them into groups.

The second way involves the use of the designed compensator only at the stage of formation of work in progress during group assembly. In this case, the compensator replaces one of the parts, the most suitable in form. In the design of Figure 1, when implementing the group interchangeability method, the compensator is not initially used, a sleeve similar to part 1 is made instead of it. When work in progress appears, production and installation of a combined compensator is assumed as a link $A_{1}$ instead of the sleeve.

\section{Conclusion}

1. A technology to apply a compensator during assembly using the group interchangeability method has been developed. It is implemented in two ways: the inclusion of a compensator into each dimensional chain collected by the group interchangeability method; the use of a compensator only at the stage of formation of work in progress during group assembly by replacing one of the parts with it.

2. When implementing the methods, the information advantage of the selective assembly is used - information about the actual dimensions of the parts (links) necessary to sort the parts into groups. This eliminates the step of measuring the closing link during assembly and simplifies the design of the compensator, reducing the number of control steps. 


\section{References}

1. Altschul R. (1994), Case study in statistical tolerancing. Manufacturing Review of the AMSE, 1994, №7, P. 52-56.

2. Anurev V.I. (2001) Reference book for designer-mechanical engineer: In 3 v. V.2. 8th ed., rev. and add.; Ed. I.N. Zhestkova. Moscow: Mashinostroenie, 2001, 912 p., Russia.

3. Bezyazyachny V.F., Nepomiluyev V.V. Possible ways to improve the quality of manufacturing engineering products. Assembly in mechanical engineering, instrument making.2015,№ 1. P. 17-20. Russia.

4. Chase, K.W., Gao, J., Magleby, S.P., Sorensen, C.D. (1996) Including geometric feature variations in tolerance analysis of mechanical assemblies. IE Transactions (Institute of Industrial Engineers), 28 (10), pp. 795-807.

5. Goldfarb, V., Malina, O., Trubachev, E (2016) New concept of the process of designing gearboxes and gear systems. Mechanisms and Machine Science 34, P. 405423.

6. Henzold, G. (2006) Geometrical dimensioning and tolerancing for design Manufacturing and Inspection. 2nd Edition - Elsevier: Oxford, UK, 2006, 416 p.

7. Kolesov, IM (1999) Fundamentals of mechanical engineering technology: a textbook. 2nd ed., Corr. Moscow: Higher. school., 1999, 591 p., Russia.

8. Laaneots R. (2004) Modified calculation method of tolerance of dimensional chain dependent link. $4^{\text {th }}$ international DAAAM symposium «Industrial engineering innovation as competitive edge SME» Tallinn, Estonia, 2004, P. 43-46.

9. Lebedevsky M.S., Weitz V.L., Fedorov A.I. (1985) Scientific basis of automatic assembly. Moscow: Mashinostroenie, 1985, 316 p., Russia.

10. Mishunin V.P. Osetrov V.G. (2002) Optimization in achieving the accuracy of the axial clearance in the gearboxes. Assembly in mechanical engineering, instrument making. 2002, №6, P. 2-4, Russia.

11. Nepomiluev V.V., Oleynikova E.V., Gusarova N.I. (2015) Probabilistic-statistical model of the process of individual selection. Intelligent systems in production. 2015, № 1, P. 8-13, Russia.

12. Osetrov V.G., Slashchev E.S. Assembly in mechanical engineering, instrument making. Theory technology and organization. Izhevsk: IICP, 2015. - 328 p.

13. Osetrov V.G., Slashchev E.S. (2014) Improving the calculations of the dimensional chain when using the method of group interchangeability. Assembly in mechanical engineering, instrument making. 2014, №7, P. 24-29, Russia.

14. Osetrov V.G., Slashchev E.S. (2014) The calculation of the accuracy of compounds with tension when using the method of group interchangeability. Intelligent systems in production. 2014, № 2 (24), P. 52-56, Russia.

15. Scholz, F. (1995) Tolerance Stack Analysis Methods Research and Technology. Boeing Information \& Support Services, 1995, 44 p.

16. Sorokin M.N., Anurov Y.N. (2011) Formalization of the method of intergroup interchangeability in the implementation of selective assembly of products. Assembly in mechanical engineering, instrument making. 2011, №8, P. 16-19, Russia.

17. Sorokin M.N., Anurov Y.N. (2016) Rolling bearing assembly. Assembly in mechanical engineering, instrument making. 2016, № 2, P 18-23, Russia.

18. Srinivasan V. (2008) Standardizing the specification, verification, and exchange of product geometry Research, status and trends. Computer-Aided Design., 2008, №40 (7), P. 738-749. 
19. Sun Y., Gupta M. (2004) Optimization of a flat due. Mechanical Engineering Engineering Mechanics Department Michigan Technological University Houghton, ANTEC 2004, P. 3007-3011.

20. Voyachek I.I. (2006) Integrated design of fixed couplings: monograph. Penza: Penza State University, 2006, 208 p., Russia.

21. Malikova, D.M., Slashchev, E.S., Istomin, E.P., Vagizov, M.R., Kolbina, O.E. (2020) Method for solving problems of the theory restrictions of infocommunication systems using linear equations with many unknowns. IOP Conference Series: Earth and Environmental Science, 2020, 507(1), 012018.

22. Shilyaev, S., Slashchev, E., Mikhaylov, Y. (2020) The method for achievement of group interchangeability accuracy for multilink dimension chains with gaps. IOP Conference Series: Materials Science and Engineering, 2020, 709(2), 022033.

23. Voyachek, I.I., Slashchev, E.S., Malikova, D.M. (2020) Feasibility Study of Applying Group Interchangeability Method for Assembly Components of Machines. Lecture Notes in Mechanical Engineering, 2020, c. 271-280.

24. Osetrov, V.G., Slashchev, E.S., Malikova, D.M., Shilyaev, S.A., Shaikhov, R.F. (2020) Deterministic approach to reducing the labor intensiveness and enterprises product lifecycle cost management. Journal of Advanced Research in Dynamical and Control Systems, 2020, 12(2 Special Issue), c. 391-395. 